\title{
Evaluation of accuracy and reliability of the plaque reduction neutralization test (micro-PRNT) in detection of yellow fever virus antibodies
}

\author{
Marisol Simões ${ }^{\mathrm{a}, *}$, Luiz Antonio B. Camacho ${ }^{\mathrm{b}}$, Anna M.Y. Yamamura ${ }^{\mathrm{a}}$, Emily Hime Miranda ${ }^{\mathrm{a}}$, \\ Ana Carolina R.A. Cajaraville ${ }^{a}$, Marcos da Silva Freire ${ }^{c}$

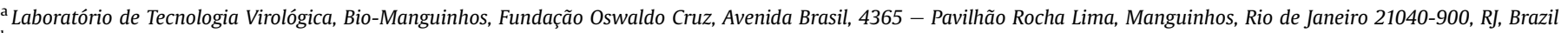

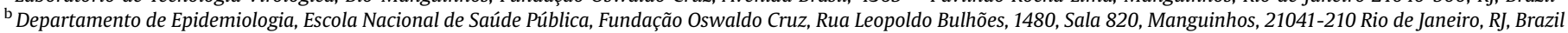 \\ ${ }^{\mathrm{c}}$ Vice-diretoria de Desenvolvimento Tecnológico de Bio-Manguinhos, Fundação Oswaldo Cruz, Avenida Brasil, 4365 - Manguinhos, Rio de Janeiro 21040-900, RJ, Brazil
}

\section{A R T I C L E I N F O}

\section{Article history:}

Received 21 June 2012

Received in revised form

24 August 2012

Accepted 7 September 2012

\section{Keywords:}

Yellow fever

Neutralizing antibody

PRNT

Reliability

Accuracy

\begin{abstract}
A B S T R A C T
Yellow fever is a disease caused by the prototype virus of the genus Flavivirus and remains endemic in tropical forest regions from Africa and South America, despite the availability of effective vaccines. These are capable of inducing a rapid specific immune response, with the formation of neutralizing antibodies that appear early, are protective and long lasting. The Plaque Reduction Neutralization Test is considered the most sensitive and specific test for quantification of neutralizing antibodies, and the reference method for assessing the protective immune response after vaccination. This study evaluated the reliability (repeatability and reproducibility) and accuracy (sensitivity, specificity and overall accuracy) of micro-PRNT50 and compared its performance with the micro-PRNT90. Although the micro-PRNT50 has showed satisfactory levels of reliability (ICCs ranged from 0.62 to 0. NorNormas e Manuais Técnicosas e Manuais Técnicos6 for repeatability and 0.72 for reproducibility) and accuracy (sensitivity of $91.1 \%$, specificity of $72.9 \%$ and overall accuracy of 78\%), the micro-PRNT90 showed higher performance, with ICCs for repeatability ranged from 0.78 to 0.79 and 0.81 for reproducibility, sensitivity of $100 \%$, specificity of $94.7 \%$ and overall accuracy of $95 \%$. Modifications in the test methodology and changes in the classification criteria in the readings of the results obtained will be important to improve the accuracy of micro-PRNT.
\end{abstract}

(c) 2012 The International Alliance for Biological Standardization. Published by Elsevier Ltd. All rights reserved.

\section{Introduction}

Yellow Fever (YF) is a disease caused by the prototype virus of the genus Flavivirus and is transmitted to humans by the bite of bloodsucking mosquitoes, mainly the Aedes and Haemagogus genera [1]. Despite the existence of effective vaccines since 1937, YF remains a major public health problem for millions of people living in endemic regions or traveling to one - largely in the tropical forests of Africa (also urban areas) and South America, where periodically disease outbreaks or epidemics take place [2].

Vaccination is the most effective way of prevention and control of YF [3]. The vaccines from 17D-204 and 17DD substrains are safe and immunogenic, inducing a rapid specific immune response,

\footnotetext{
* Corresponding author. Tel.: +55 213882 9317; fax: +55 2122604727.

E-mail addresses: marisol.simoes@bio.fiocruz.br (M. Simões), luiz.camacho@ ensp.fiocruz.br (L.A.B. Camacho), anna@bio.fiocruz.br (A.M.Y. Yamamura), emily@ bio.fiocruz.br (E.H. Miranda), anacarolina.reis@bio.fiocruz.br (A.C.R.A. Cajaraville), freire@bio.fiocruz.br (M. da Silva Freire).
}

with protective and lasting neutralizing antibodies induced within 30 days in almost all vaccines [4].

Among the serological tests available for assessing the host's specific immune response, the neutralization test is considered the most sensitive and specific [5]. It is based on the principle that infectious virus can be neutralized by specific antibodies and thereby lose the ability to infect permissive cells [6,7]. The Plaque Reduction Neutralization Test (PRNT) is the reference method to measure the immune response to vaccination or to natural infection, as titers of neutralizing antibodies. In the PRNT, from a known amount of virus, the ability of serum dilutions of an individual to prevent the formation of plaques in susceptible cells can be determined [8-10].

The plaque reduction neutralization test applied to 96-well plates (micro-PRNT) was developed to optimize resources and expedite the management of large amount of specimens, as in clinical trials of yellow fever vaccines [4,11-15]

Despite the widespread use and importance to clinical studies, the performance of the micro-PRNT has not been fully assessed. 
This study aimed to measure the reliability and accuracy of the micro-PRNT used for the determination of neutralizing antibody titers in the sera of a group of Brazilian individuals immunized with the 17DD vaccine, with reference to the PRNT applied to 6-well plates. The best cut-off point of the test was also determined.

\section{Material and methods}

\subsection{Serum samples}

For this study, we used sera from 200 Brazilian adult males who participated in a dose-response study of the 17DD YF vaccine. The sera were previously inactivated at $56{ }^{\circ} \mathrm{C}$ for $30 \mathrm{~min}$, stored at $-20^{\circ} \mathrm{C}$ and thawed prior to use. The dose-response study had been approved by the Research Ethics Committee of the Evandro Chagas Clinical Research Institute, Oswaldo Cruz Foundation (Protocol No. 0038.0.009.000-08; approved on November 10, 2008).

The sample of size 200 was estimated with the program WinPepi [16], based on the following parameters: Intraclass Correlation Coefficient (ICC) greater than or equal to 0.8 , with a significance level of $5 \%$ and breadth of the confidence interval of 0.1 . For an expected Kappa of 0.65 or more, considering the frequency of seropositive of $50 \%$, with a significance level of $5 \%$ and breadth of the confidence interval of 0.2 .

A systematic sample was selected from a total of 900 specimens sorted according to the antibody titers previously obtained in the micro-PRNT performed for the dose-response study, to represent a broad spectrum of immune responses. The operators in this study did not have access to results of the previous test.

\subsection{In-house standard for YF serum}

The standard serum prepared in-house and used as positive control (M7/100) came from Rhesus monkeys (Macaca mulatta) vaccinated against YF and was known to contain $1115 \mathrm{mIU} / \mathrm{ml}$. It had been calibrated against an international reference serum from WHO (Serum Institute Copenhagen) [13].

\subsection{Cells and virus}

Vero cells (ATCC, CCL 81) were maintained in 5\% $\mathrm{CO}_{2}$ atmosphere at $37{ }^{\circ} \mathrm{C}$ in 199 medium with Earle's salts (10X) supplemented with $5 \%$ inactivated fetal bovine serum, buffered with sodium bicarbonate $4.4 \%, 1 \%$ gentamicin sulfate and $0.4 \%$ fungizon (for each $100 \mathrm{ml}$ ). The cell concentration used for the micro-PRNT was $2.7 \times 10^{5} / \mathrm{cm}^{2}$. The concentration used for PRNT was $1.0 \times 10^{5} /$ $\mathrm{cm}^{2}$, which were seeded in 6 -well plates 24 h before the test to be performed (preformed monolayers).

The challenge virus used was a secondary seed-lot $17 \mathrm{D} / \mathrm{WHO}$ $213 / 77 / B R-1 B / 86$. At the time of use, an aliquot of virus was reconstituted with $1 \mathrm{ml}$ of sterile distilled water and it remained at rest for at least $10 \mathrm{~min}$ for complete reconstitution of the lyophilisate. After this period, the aliquot was vigorously homogenized and diluted (in medium for PRNT) to obtain an average of 30 plaques per well in 96-well plates (previously determined by viral titration).

\subsection{Micro-PRNT (96-well plates)}

For each test, serial two-fold dilutions starting at $1: 5$ in $50 \mu \mathrm{L}$ of each one of the 200 inactivated serum samples were performed in 96-well tissue culture plates (columns 1 to 10 of each plate, where each column received a different serum sample) (Fig. 1). A positive monkey serum sample (M7/100) with YF antibody content calibrated by a WHO International Reference Preparation was included

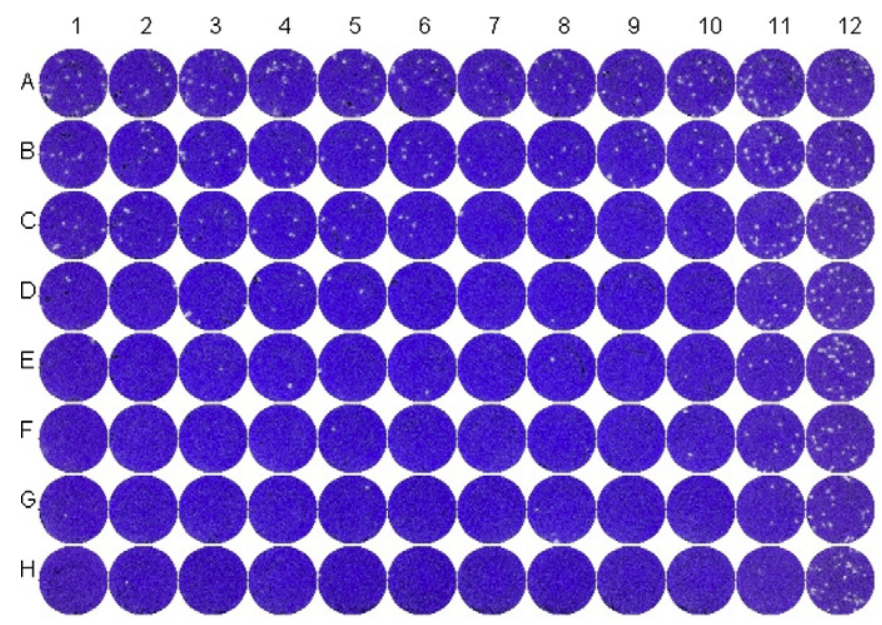

Fig. 1. Photo of a plate subjected to micro-PRNT (96-well plates). From left to right: columns 1-10 - serum samples. Column 11 - in-house standard serum (M7/100). These sera were submitted to serial dilutions starting at 1:5 to 1:640. Column $12-$ virus control.

in each set of test (column 11). After the stage of serial dilutions of sera, a suspension of the challenge virus (the concentration required to obtain an average of thirty plaque forming units in $50 \mu \mathrm{L}$ ) was dispensed into all wells. Dilutions of virus and sera were performed in 199 medium containing 2.5\% Hepes $1 \mathrm{M}$. Column 12 of each plate was designed to virus control (Fig. 1). In the step of neutralization, the mix (virus plus sera) was incubated for $1 \mathrm{~h}$ at room temperature. After this incubation, $50 \mu \mathrm{L}$ of a suspension of Vero cells in 199 medium (density of $2.7 \times 10^{5} / \mathrm{cm}^{2}$ ) were added to all wells and the plates incubated again at $37^{\circ} \mathrm{C}$ in BOD incubator for $3 \mathrm{~h}$. After this period, the medium was completely discarded and replaced with 199 medium containing 3\% carboxymethyl cellulose (CMC) in volumes of $100 \mu \mathrm{L}$. After incubation at $37{ }^{\circ} \mathrm{C}$ in $5 \% \mathrm{CO}_{2}$ atmosphere for six days, the monolayers were fixed with formalin (10\%), stained with crystal violet $(0.04 \%)$ and plaques were counted at a magnification of $12.5 \times$ on a vertically mounted $35 \mathrm{~mm}$ projector with wide angle lens $[13,17]$.

\subsection{PRNT (6-well plates)}

The serial four-fold dilutions (in 199 medium) of the 200 sera (including the standard serum) were performed on plates of 24 wells, in order to obtain dilutions of 1:16 to 1:16384. After this step, $500 \mu \mathrm{L}$ of each serum dilution were mixed with $500 \mu \mathrm{L}$ of viral suspension in a second 24-well plate (reconstitution and dilution of the virus were performed previously to obtain 30-40 plaques per well). The same procedure was performed to virus control: $800 \mu \mathrm{L}$ of the virus suspension was mixed with $800 \mu \mathrm{L}$ of diluent medium. For neutralization, the mix virus plus serum was incubated for $1 \mathrm{~h}$ at $37^{\circ} \mathrm{C}$ in $5 \% \mathrm{CO}_{2}$ atmosphere. Medium from 6 -well plates (seeded $24 \mathrm{~h}$ before, with Vero cells in a density of $1.0 \times 10^{5} / \mathrm{cm}^{2}$ ) was removed and replaced with $200 \mu \mathrm{L}$ of the virus-serum mixtures described above (in triplicate for each serum dilution). The monolayers were incubated for $1 \mathrm{~h}$ at $37{ }^{\circ} \mathrm{C}$ in $5 \% \mathrm{CO}_{2}$ atmosphere. After this incubation, the mixtures were aspirated and replaced with $3 \mathrm{ml}$ of $\mathrm{CMC} 3 \%$. After seven days incubation at $37{ }^{\circ} \mathrm{C}$ in $5 \% \mathrm{CO}_{2}$ atmosphere, the monolayers were fixed with formalin (10\%), stained with crystal violet $(0.04 \%)$ and plaques were counted under a magnification of $12.5 \times[12,13]$. The test set in Fig. 2 illustrates the size and distribution of the plaques. 


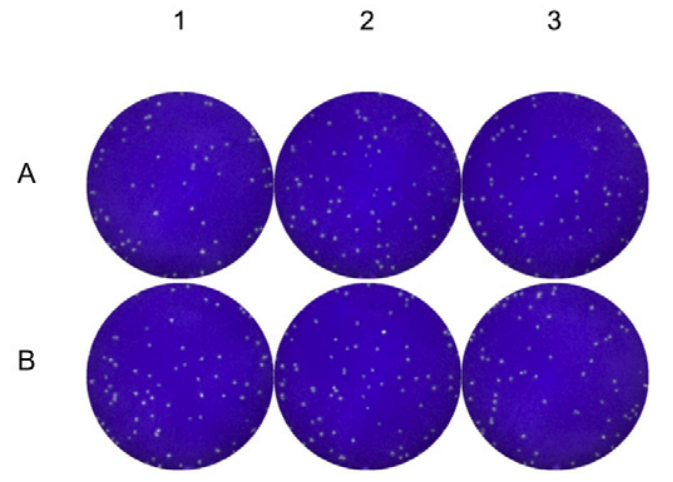

Fig. 2. Photo of a 6-well plate resulting from PRNT. The six wells correspond to the virus control.

\subsection{Calculations}

The PRNT titer was defined as the reciprocal of the last serum dilution that reduced the number of plaques (obtained in the virus control) by $50 \%$ or $90 \%$. The $50 \%$ endpoint $\left(\mathrm{EP}_{50}\right)$ of the test was determined by multiplying the arithmetic mean of the number of plaques corresponding to the virus control by 0.5 . To determine the 90\% EP (EP90), the arithmetic mean of the number of plaques corresponding to the virus control was multiplied by 0.1 . The serum dilution which reduced the number of plaques by $50 \%$ or $90 \%$ was calculated through linear regression using Microsoft Excel 2007 by interpolation of the dilutions corresponding to the plaque numbers immediately above and below the $50 \%$ or $90 \%$ endpoint value of the test. The antibody concentration in $\mathrm{mIU} / \mathrm{ml}$ was calculated relative to the antibody content in the international reference. The quotient of the division of $1115 \mathrm{mIU} / \mathrm{ml}$ (titer referring to $\mathrm{M} 7 / 100$ ) by the dilution corresponding to the $50 \%$ or $90 \%$ endpoint of the reference is multiplied by the dilution equivalent to the $50 \%$ or $90 \%$ endpoint of each serum sample. The base line was calculated at the lowest dilution of sera (1:5 and 1:16 for micro-PRNT and PRNT, respectively), as it corresponds to the detection limit of the test.

\subsection{Operators}

Three operators previously trained for the implementation of PRNT and micro-PRNT participated in this study. A rotation of operators arranged in pairs (named $\mathrm{A}, \mathrm{B}$ and $\mathrm{C}$ ) was made to perform the micro-PRNT. The "main" operator was responsible for the addition of diluent medium, the viral and cell suspensions and $\mathrm{CMC}$, dilution of the virus, serial dilutions of sera and counting the plaques obtained. The "auxiliary" operator was responsible for placing the serum sample in wells of the first lines of each plate.

\subsection{Statistical analysis}

We calculated the means, standard deviations (SD) and coefficients of variation (CV) of the nine results for each of the 200 sera resulting from three repetitions for each one of the three pairs of operators. The CV also was used to evaluate the means of plaques counted in triplicate for each dilution of serum and virus controls. Tests with the CV of the virus control greater than $20 \%$ were discarded and repeated.

Repeatability was evaluated from three independent repetitions of the micro-PRNT for each one of the 200 sera, performed by the same pair of operators. In order to evaluate the reproducibility of the test, the other two pairs of operators performed the same procedures and the third routine of each pair was considered in the assessment of the level of agreement between them. The repetitions were performed under the same conditions (inputs, materials, equipment, dilutions of viruses and sera, incubation etc.). Each routine of the micro-PRNT (determined by different dates) was performed for the 200 serum samples. The agreement of quantitative results was determined by the ICC [18], with $95 \%$ confidence intervals.

Accuracy of the micro-PRNT to determine the neutralizing antibody titer against YF virus was measured by reference to the PRNT in 6-well plates. This is considered the best existing method to determine the neutralizing antibodies to YF. Accuracy parameters used in this study included sensitivity (probability of the serum sample to be reactive - positive test - in individuals who have neutralizing antibodies against YF virus) and specificity (probability of the serum sample not to be reactive - negative test - in individuals who have not antibodies). A Receiver Operating Characteristic (ROC) curve was constructed by plotting the estimates of sensitivity against the false positive rates for a series of cut-off points. It revealed the best cut-off point of the test, that is, one that gives us at the same time, the best sensitivity and specificity for the micro-PRNT [19]. The cut-off point for the PRNT ( 6 wells) was determined in the histogram of antibody titers from all 200 sera.

The results of the two methodologies (96-well and 6-well plates) were organized in Microsoft Excel 2007 and statistical analysis was carried out using the Statistical Package for Social Science V.17.0 (SPSS Institute Inc., 1990). The results are shown in $\mathrm{mIU} / \mathrm{ml}$ and in reciprocal of dilution.

\section{Results}

The ICCs of the pairs of operators in the analysis of repeatability of the micro-PRNT 50 (50\% endpoint) are shown in Table 1. For analysis of reproducibility the ICC among the three pairs of operators was 0.72 (0.66-0.78).

The histogram of antibody titers from the 200 sera submitted to the PRNT $_{50}$ showed a well-defined separation of sera with results smaller or larger than $2.5 \log _{10} \mathrm{mIU} / \mathrm{ml}$ (Fig. 3A). These results were consistent with the immune status expected from the source of the sera (Fig. 3B) with 144 sera (125 pre- and 19 post-vaccination sera) showing antibody titers between 2.0 and $2.5 \log _{10} \mathrm{mIU} / \mathrm{ml}$, and 56 sera (26 pre-vaccination sera, marked with asterisks on the graph, and 30 post-vaccination sera) higher than $2.5 \log _{10} \mathrm{mIU} / \mathrm{ml}$. The distribution of post-vaccination antibody titers shifted to higher values although mixed with low titers. The cut-off point of $2.5 \log _{10}$

Table 1

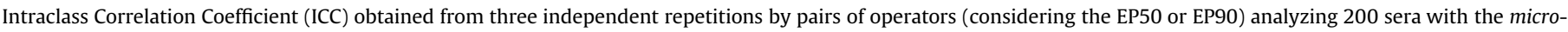
PRNT.

\begin{tabular}{|c|c|c|c|c|}
\hline \multirow{2}{*}{$\begin{array}{l}\text { Pair of } \\
\text { operators }\end{array}$} & \multicolumn{2}{|l|}{$\operatorname{ICC}\left(\mathrm{Cl}_{95 \%}\right)$} & \multicolumn{2}{|c|}{ ICC of the mean $\left(\mathrm{Cl}_{95 \%}\right)$} \\
\hline & $50 \%$ endpoint & $90 \%$ endpoint & $50 \%$ endpoint & $90 \%$ endpoint \\
\hline $\mathrm{A}$ & $0.64(0.53-0.73)$ & $0.79(0.74-0.83)$ & $0.84(0.77-0.89)$ & $0.92(0.90-0.94)$ \\
\hline $\mathrm{B}$ & $0.62(0.50-0.70)$ & $0.78(0.73-0.83)$ & $0.83(0.75-0.88)$ & $0.92(0.89-0.93)$ \\
\hline $\mathrm{C}$ & $0.76(0.70-0.81)$ & $0.79(0.73-0.84)$ & $0.90(0.88-0.93)$ & $0.92(0.89-0.94)$ \\
\hline
\end{tabular}

$\mathrm{Cl}_{95 \%}=95 \%$ confidence interval. 

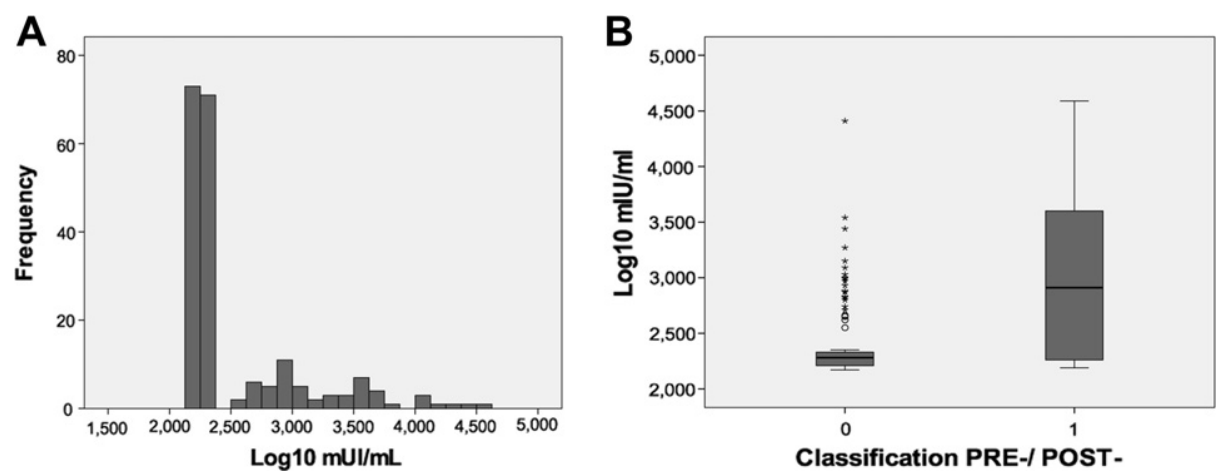

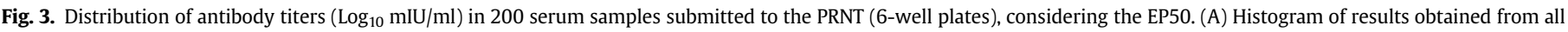
sera; (B) Boxplot comparing the classification of sera - pre- (0) and post-vaccination (1) - with their results.

$\mathrm{mIU} / \mathrm{ml}$ (316 $\mathrm{mIU} / \mathrm{ml}$ or $1: 10)$ for the $\mathrm{PRNT}_{50}$ appeared to be suitable and was therefore used for data analysis.

The results from PRNT were consistent with the origin of the sera disclosed after completion of laboratory analysis, and showing 151 pre-vaccination sera and 49 post-vaccination sera.

The frequency distribution of antibody titers from micro-PRNT 50 did not show a well-defined separation of seropositive and seronegative specimens (Fig. 4).

The ROC curve showed that the limit value of $2.9 \log _{10} \mathrm{mIU} / \mathrm{ml}$ ( $794 \mathrm{mIU} / \mathrm{ml}$ or $1: 50$ ) provided the best combination of sensitivity and specificity for the test: in the upper left corner of the graph and the farthest from the reference line, indicating a greater overall accuracy (Fig. 5).

With PRNT $_{90} 187$ (out of 200) sera presented results less than $2.9 \log _{10} \mathrm{mIU} / \mathrm{ml}$, of which 148 were pre-vaccination and 39 sera were post-vaccination, with clearly distinct distribution from the subset of higher values, which 13 sera showed results higher than $2.9 \log _{10} \mathrm{mIU} / \mathrm{ml}$ (10 post-vaccination sera and 3 pre-vaccination sera) (Fig. 6A). The cut-off point for the PRNT 90 of $2.9 \log _{10} \mathrm{mIU} /$ $\mathrm{ml}(794 \mathrm{mIU} / \mathrm{ml}$ or $1: 10)$ was used for data analysis.

The construction of a frequency histogram considering the averages of the results of 200 sera submitted to the micro-PRNT

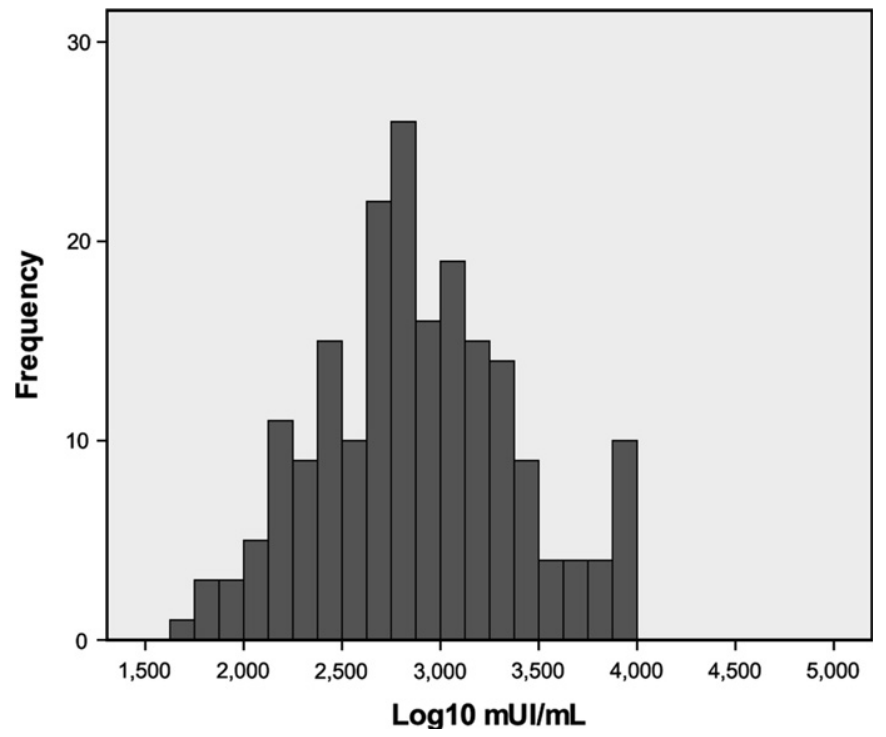

Fig. 4. Histogram of the average (expressed in $\log _{10} \mathrm{mIU} / \mathrm{ml}$ ) of the results obtained from the 9 routines for each of the 200 sera submitted to the micro-PRNT, considering the EP50. based on EP90 did not clearly indicate, as well as for micro-PRNT 50 , the limit values to define seropositivity (Fig. 6B).

The criterion that best discriminated the immune status of individuals was defined by estimating the parameters of accuracy corresponding to various "cut-off points" for the micro-PRNT 90 (taking the $\mathrm{PRNT}_{90}$ as reference) in order to define the best among them. The cut-off point of $3.4 \log _{10} \mathrm{mIU} / \mathrm{ml}(2512 \mathrm{mIU} / \mathrm{ml}$ or $1: 13)$ provides the best measures of accuracy.

Determination of the ideal cut-off points for the micro-PRNT ${ }_{50}$ and the micro-PRNT 90 allowed us compare them. The measures of accuracy of the micro-PRNT 50 (sensitivity of 91.1\%, specificity of $72.9 \%$ and overall accuracy of $78 \%$ ) were lower than for the microPRNT $_{90}$ (sensitivity of $100 \%$, specificity of $94.7 \%$ and overall accuracy of 95\%), showing its superior performance.

The repeatability (Table 1 ) and reproducibility of the micro$\mathrm{PRNT}_{90}$ were evaluated as for micro-PRNT 50 . In the analysis of reproducibility of the micro-PRNT 90 the ICC obtained between the three pairs of operators was $0.81(0.77-0.85)$.

\section{Discussion}

The PRNT has been extensively used to quantify neutralizing antibodies [4,11-15], which is the major immune response to vaccination or natural infection with the YF virus $[6,10]$. Although a serological correlate of protection against YF is unknown, there is

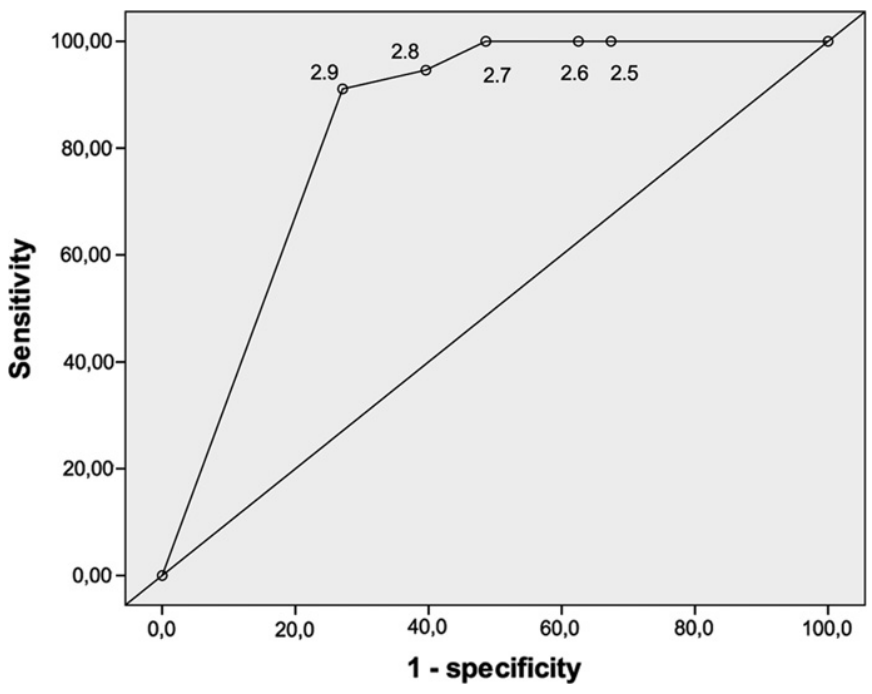

Fig. 5. ROC curve with different cut-off points for the micro-PRNT ${ }_{50}$. 
A

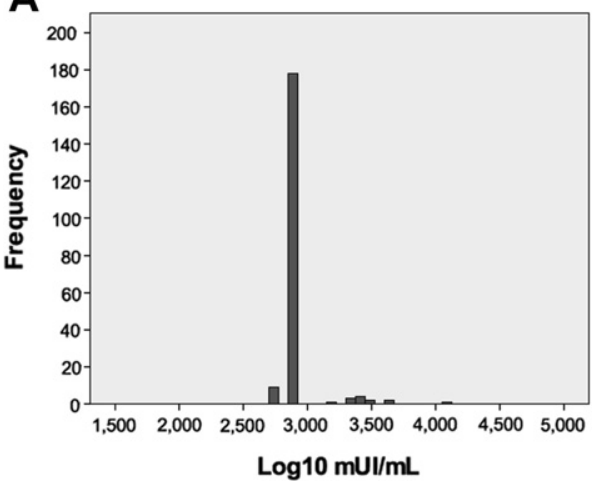

B

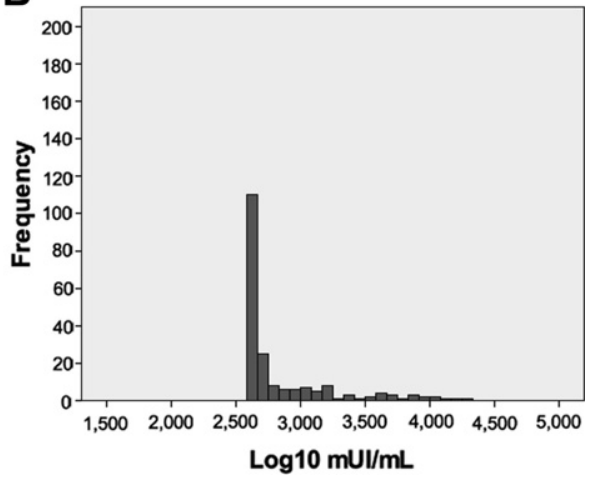

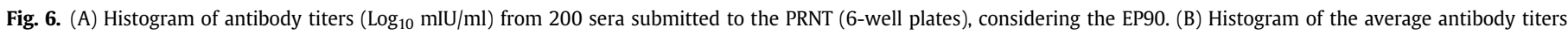
$\left(\log _{10} \mathrm{mIU} / \mathrm{ml}\right.$ ) obtained from the 9 routines for each one of the 200 sera submitted to the micro-PRNT (96-well plates), considering the EP90.

indirect evidence of protection in vaccinated individuals who visited or lived in endemic areas.

The reliability of the micro-PRNT 50 in this study was satisfactory compared to others with similar methods and population in which the ICC was $0.79(0.74-0.83)[4,20]$.

The accuracy of the neutralization test had been shown to be superior to ELISA and hemagglutination inhibition [9]. The microPRNT also appeared to be satisfactory for the comparative assessment of immunogenicity of vaccines, but a thorough assessment of its performance had not been conducted before. To address that issue, vaccinees had the advantage of being widely available. Given high vaccine coverage in endemic areas in Brazil, clinical YF and subclinical natural infection are hard to detect. Typical natural infections are expected to elicit strong immune responses, whereas vaccination induces a wide range of antibody levels, which is a desirable property for analysis of reliability and accuracy.

Considering that PRNT is the standard for antibody titration, and that clinical elements indicating infection were not available, the PRNT in 6-well plates was considered the appropriate reference for accuracy assessment of the micro-PRNT. The cut-off point for seropositivity was based on data generated in this study, including vaccination status. Those data supported PRNT in 6-well plates as the reference test.

The $90 \%$ endpoint, which has been used for analysis of results from neutralization tests [9,21-24], was used in the micro-PRNT and showed the best performance, with accuracy measures higher than for the micro-PRNT ${ }_{50}$. That was consistent with the higher proportion of seronegative results in pre-vaccination sera, and also expected considering the more restrictive criterion for neutralization. Nevertheless, performance of the micro-PRNT 90 could be improved with the use of an in-house standard serum with higher neutralizing antibody titer.

This study indicated opportunities to improve the micro-PRNT. Changes in the classification criteria of the sera (using the best cutoff point and the $50 \%$ or $90 \%$ endpoint) undergoing to the test are important issues to be discussed to improve the accuracy of the micro-PRNT. Laboratory methods should also be revised according to Cohen et al. [25] who (in personal communication) do not recommend the use of room temperature in the step of neutralization of the micro-PRNT. They argue that "room temperature" is not well established, is subject to climatic variations and, therefore, is an uncontrolled variable. Other procedures, such as the way to remove the supernatant before the addition of $\mathrm{CMC}$, are also thought to contribute to variation in the results from the same serum. To incubate the plates for the neutralization step at $37{ }^{\circ} \mathrm{C}$ atmosphere is an alternative to safeguard against changes in room temperature. Also, to discard supernatant after the adsorption step, the use of pre-formed monolayer and aspiration of the supernatant can be used, as for the PRNT. The quality of the cell monolayer is critical for the development of plaques and, thus, to generate accurate results.

Accuracy estimates of the micro-PRNT had an intrinsic methodological limitation as the weaknesses of the reference standard are necessarily disregarded in the process. Therefore, the actual sensitivity and specificity for the true immune status was probably somewhat lower. On the other hand, taking the average titer of 9 tests of each specimen, resulted in more reliable measurements, and inflated the accuracy estimates.

The quest for accurate methods can be framed by the implications of false negatives (missing immune subjects) and false positives (missing susceptible subjects) for diagnostic investigation, disease surveillance and assessment of vaccine immunogenicity.

\section{Financial support}

This work was supported by Fiotec and by Bio-Manguinhos, Fiocruz. The funding sources had no involvement in study design; in the collection, analysis and interpretation of data; in the writing of the report; and in the decision to submit the article for publication.

\section{Acknowledgments}

We thank the technical team from Latev for providing reagents, materials and equipment. We thank Dr Reinaldo M. Martins for allowing the use of sera and Carlos A. Frota for separating the serum samples.

\section{References}

[1] Monath TP. Yellow fever: an update. Lancet Infect Dis 2001;1(1):11-20.

[2] Tomori O. Yellow fever: the recurring plague. Crit Rev Clin Lab Sci 2004;41(4): 391-427.

[3] World Health Organization, http:/www.who.int/mediacentre/factsheets/ fs100/en/; 2009 [Accessed 01.17.2010].

[4] Camacho LA, Freire MS, Leal MLF, Aguiar SG, Nascimento JP, Iguchi T, et alCollaborative Group for the Study of Yellow Fever Vaccines. Immunogenicity of WHO-17D and Brazilian 17DD yellow fever vaccines: a randomized trial. Rev Saude Publica 2004;38(5):671-8.

[5] Monath TP. Yellow fever vaccine. In: Plotkin S, Orenstein WA, editors. Vaccines. 4th ed. Phildelphia: Elsevier; 2004. p. 1095-176.

[6] Secretaria de Vigilância em Saúde. Guia de vigilância epidemiológica - Febre amarela. Normas e Manuais Técnicos, http://portal.saude.gov.br/portal/ arquivos/pdf/febre_amarela_gve.pdf; 2005.

[7] Santos NOS, Benati FJ. Diagnóstico laboratorial das viroses. In: Santos NSO, Romanos MTV, Wigg MD, editors. Introdução à virologia humana. 2nd ed. Rio de Janeiro: Guanabara Koogan S.A; 2008. p. 83-116. 
[8] De Madrid AT, Porterfield JS. A simple micro-culture method for the study of group B arboviruses. Bull World Health Organ 1969;40(1):113-21.

[9] Niedrig M, Lademann M, Emmerich P, Lafrenz M. Assessment of IgG antibodies against yellow fever virus after vaccination with $17 \mathrm{D}$ by different assays: neutralization test, hemagglutination inhibition test, immunofluorescence assay and ELISA. Trop Med Int Health 1999;4(12):867-71.

[10] Roehrig JT, Hombach J, Barrett AD. Guidelines for plaque-reduction neutralization testing of human antibodies to dengue viruses. Viral Immunol 2008; 21(2):123-32.

[11] Galler R, Pugachev KV, Santos CL, Ocran SW, Jabor AV, Rodrigues SG, et al Phenotypic and molecular analyses of yellow fever 17DD vaccine viruses associated with serious adverse events in Brazil. Virology 2001;290(2):309-19.

[12] Marchevsky RS, Freire MS, Coutinho ES, Galler R. Neurovirulence of yellow fever 17DD vaccine virus to rhesus monkeys. Virology 2003;316(1):55-63.

[13] Freire MS, Mann GF, Marchevsky RS, Yamamura AM, Almeida LF, Jabor AV, et al. Production of yellow fever 17DD vaccine virus in primary culture of chicken embryo fibroblasts: yields, thermo and genetic stability, attenuation and immunogenicity. Vaccine 2005;23(19):2501-12.

[14] Marchevsky RS, Leal ML, Homma A, Coutinho ES, Coutinho ES, Camacho LA et al. Molecular and phenotypic analysis of a working seed lot of yellow fever virus 17DD vaccine strain produced from the secondary seed lot 102/84 with an additional passage in chicken embryos. Biologicals 2006;34(3):191-7.

[15] Camacho LAB, Freire MS, Leal MLF, Maia MLS, Martins RM, Collaborative Group for Studies with Yellow Fever Vaccine. Randomized, double-blind, multicenter study of the immunogenicity and reactogenicity of 17DD and WHO 17D-213/77 yellow fever vaccines in children: implications for the Brazilian National Immunization Program. Vaccine 2007;25(16):3118-23.

[16] Abramson JH. WINPEPI (PEPI-for-Windows): computer programs for epidemiologists. Epidemiol Perspect Innov 2004;1(1):6.
[17] Stefano I, Sato HK, Pannuti CS, Omoto TM, Mann G, Freire MS, et al. Recent immunization against measles does not interfere with the sero-response to yellow fever vaccine. Vaccine 1999;17(9-10):1042-6.

[18] Mcgraw KO, Wong SP. Forming inferences about some intraclass correlation coefficients. Psychol Methods 1996;1(1):30-46.

[19] Greiner M, Pfeiffer D, Smith RD. Principles and practical application of the receiver-operating characteristic analysis for diagnostic tests. Prev Vet Med 2000;45:23-41.

[20] Szklo M, Nieto FJ. Quality assurance and control. In: Szklo M, Nieto FJ, editors. Epidemiology: beyond the basics. Maryland: Aspen Publishers; 2000. p. 343-404.

21] Johnson BW, Kosoy O, Martin DA, Noga AJ, Russell BJ, Johnson AA, et al. West Nile virus infection and serologic response among persons previously vaccinated against yellow fever and Japanese encephalitis viruses. Vector Borne Zoonotic Dis 2005;5(2):137-45.

22] Santaella J, McLean R, Hall JS, Gill JS, Bowen RA, Hadow HH, et al. West Nile virus serosurveillance in Iowa white-tailed deer (1999-2003). Am J Trop Med Hyg 2005;73(6):1038-42.

[23] Dobler G, Wölfel R, Schmüser H, Essbauer S, Pfeffer M. Seroprevalence of tickborne and mosquito-borne arboviruses in European brown hares in Northern and Western Germany. Int J Med Microbiol 2006;296:80-3.

[24] Sondgeroth K, Blitvich B, Blair C, Terwee J, Junge R, Sauther M, et al. Assessing flavivirus, lentivirus, and herpesvirus exposure in free-ranging ring-tailed lemurs in southwestern Madagascar. J Wildl Dis 2007;43(1):40-7.

[25] Cohen BJ, Audet S, Andrews N, Beeler J, WHO Working Group on Measles Plaque Reduction Neutralization Test. Plaque reduction neutralization tes for measles antibodies: description of a standardised laboratory method for use in immunogenicity studies of aerosol vaccination. Vaccine 2007;26(1): 59-66. 